\title{
Examining the Impact of Question Construction on Reporting of Sexual Identity: Survey Experiment Among Young Adults
}

William J Young ${ }^{1}$, PhD; Michelle T Bover Manderski ${ }^{1,2}$, MPH, PhD; Ollie Ganz ${ }^{1,3}$, MSPH, DrPH; Cristine D Delnevo ${ }^{1,3}$, MPH, PhD; Mary Hrywna ${ }^{1,3}$, MPH, PhD

\footnotetext{
${ }^{1}$ Center for Tobacco Studies, Rutgers Biomedical and Health Sciences, Rutgers University, New Brunswick, NJ, United States

${ }^{2}$ Department of Biostatistics and Epidemiology, Rutgers School of Public Health, Rutgers University, Piscataway, NJ, United States

${ }^{3}$ Department of Health Behavior, Society and Policy, Rutgers School of Public Health, Rutgers University, Piscataway, NJ, United States
}

\section{Corresponding Author:}

William J Young, PhD

Center for Tobacco Studies

Rutgers Biomedical and Health Sciences

Rutgers University

303 George Street

Suite 500

New Brunswick, NJ, 08901

United States

Phone: 18489328054

Email: william.j.young@rutgers.edu

\section{Abstract}

Background: Compared with heterosexuals, sexual minorities in the United States experience a higher incidence of negative physical and mental health outcomes. However, a variety of measurement challenges limit researchers' ability to conduct meaningful survey research to understand these disparities. Despite the prevalence of additional identities, many national health surveys only offer respondents 3 substantive options for reporting their sexual identities (straight/heterosexual, gay or lesbian, and bisexual), which could lead to measurement error via misreporting and item nonresponse.

Objective: This study compared the traditional 3-option approach to measuring sexual identity with an expanded approach that offered respondents 5 additional options.

Methods: An online survey experiment conducted among New Jersey residents between March and June 2021 randomly assigned 1254 young adults (ages 18-21) to answer either the 3-response measure of sexual identity or the expanded item. Response distributions for each measure were compared as were the odds of item nonresponse.

Results: The expanded version of the question appeared to result in more accurate reporting among some subgroups and induced less item nonresponse; $12 \%$ (77/642) of respondents in the expanded version selected a response that was not available in the shorter version. Females answering the expanded item were less likely to identify as gay or lesbian $(2.1 \%$ [10/467] vs. $6.6 \%$ [30/457]). Females and Non-Hispanic Whites were slightly more likely to skip the shorter version than the longer version $(1.1 \%$ [5/457 for females and 3/264 for Non-Hispanic Whites] vs. 0\% [0/467 for females and 0/277 for Non-Hispanic Whites]). About $5 \%(32 / 642)$ of respondents answering the longer item were unsure of their sexual identity (a similar option was not available in the shorter version). Compared with respondents answering the longer version of the question, those answering the shorter version had substantially greater odds of skipping the question altogether (odds ratio 9.57, 95\% CI 1.21-75.74; $P=.03$ ).

Conclusions: Results favor the use of a longer, more detailed approach to measuring sexual identity in epidemiological research. Such a measure will likely allow researchers to produce more accurate estimates of health behaviors and outcomes among sexual minorities.

(JMIR Public Health Surveill 2021;7(12):e32294) doi: 10.2196/32294

\section{KEYWORDS}

survey measurement; sexual identity; survey wording experiment 


\section{Introduction}

Compared with heterosexual individuals, those identifying as sexual minorities in the United States experience a higher incidence of negative physical and mental health outcomes [1-7]. They also report higher levels of risk behaviors including tobacco, alcohol, and drug use [1,2,8-13]. Given that sexual minorities bear a disproportionate burden of risk behaviors and poor health outcomes, research to understand and address these health inequities is essential [14]. However, survey measurement challenges limit the ability to conduct meaningful research inclusive of sexual minorities. Indeed, a variety of approaches to operationalizing sexual orientation exist across national surveys, complicating estimates of risk behaviors and health outcomes among this population $[15,16]$. In fact, the National Academies of Sciences, Engineering, and Medicine commissioned a panel to review current measures and methodological issues related to measuring sexual orientation, in addition to sex and gender identity [17].

In this short paper, we contribute to the literature on measuring sexual identity by presenting the results of a randomized experiment comparing 2 measurement approaches. It is well established in the literature on survey methods that question design can affect respondents' motivation to respond accurately, or even at all, to particular items [18]. If a question does not motivate respondents to answer accurately, or it encourages them to skip the item altogether (eg, item nonresponse), this can lead to measurement error [18]. One common approach to measure sexual identity asks participants to choose from 1 of 3 responses: heterosexual/straight, gay or lesbian, and bisexual. This 3-response approach, or a close variation of it, is the one taken by several national surveys, including the National Health Interview Survey [19], Behavioral Risk Factor Surveillance System [20], and the National Survey on Drug Use and Health [21]. Despite the popularity of this approach, these 3 responses do not constitute an exhaustive list of sexual identities that one may claim [22]. In failing to offer a broader range of options, surveys employing the 3-response approach are susceptible to measurement error, either because respondents report an inaccurate sexual identity or because they skip the item altogether if they believe it does not represent their actual identities.

\section{Methods}

To explore the impact of question construction on measurement of sexual identity, we randomly assigned a diverse group of
1254 young adults, aged 18-21 years, to answer either the traditional, 3-response version of the sexual identity item $(\mathrm{n}=612)$ or an expanded version offering more response options $(n=642)$. Overall sample demographics and demographics by experimental condition are presented in Multimedia Appendix 1. The traditional, 3-category question read, "Do you consider yourself to be:" and offered 3 response options: "Heterosexual or straight," "Gay or lesbian," and "Bisexual." The longer version read, "Below is a list of terms that people often use to describe their sexuality or sexual orientation. Please select the term that best applies to you." It offered the responses, "Straight/Heterosexual," "Gay," "Lesbian," "Bisexual," "Queer," "Asexual," "Pansexual," "Questioning/Not sure," and "Another sexual orientation not listed above (please specify)." The experiment was embedded in the first wave survey of the Policy and Communication Evaluation: New Jersey (PACE NJ) study. The survey was fielded online between March 24 and June 21,2021 . In addition to the age requirement, participants in the PACE NJ study were required to report living in New Jersey for at least four months out of the year.

\section{Results}

The expanded version of the question offers a more complete picture of respondents' sexual identities (Tables 1 and 2). In fact, $12 \%$ (77/642) of respondents answering the longer question selected a response option that was not offered in the shorter, more commonly used version of the question. Cross-tabular results revealed that the proportion of females identifying as gay or lesbian was much lower in the expanded version compared with the shorter version $(2.1 \%$ [10/467] vs. $6.6 \%$ [30/457]), as they presumably opted for terms such as queer (4.1\% [19/467]) or pansexual (2.6\% [12/467]). Females and Non-Hispanic Whites were slightly more likely to skip the shorter version than the longer version $(1.1 \%$ [5/457 for females and 3/264 for non-Hispanic Whites] vs. 0\% [0/467 for females and $0 / 277$ for Non-Hispanic Whites]). Importantly, $6.6 \%$ (31/467) of females, $6.1 \%$ (22/359) of non-White respondents, and $5 \%(32 / 642)$ overall reported questioning or being unsure of their sexuality in the expanded version. It could be, then, that some individuals avoided answering the shorter item not only because they felt the choices did not represent their identities, but also because they were unsure of their identities in the first place. 
Table 1. Response distributions by sex and race in experimental condition $1 .^{\mathrm{a}}$

\begin{tabular}{|c|c|c|c|c|c|c|c|c|c|c|}
\hline \multirow[t]{3}{*}{ Sexual identity } & \multirow{2}{*}{\multicolumn{2}{|c|}{ Overall $(\mathrm{N}=612)$}} & \multicolumn{4}{|l|}{ Sex } & \multicolumn{4}{|l|}{ Race } \\
\hline & & & \multicolumn{2}{|c|}{ Male $(n=155)$} & \multicolumn{2}{|c|}{ Female $(n=457)$} & \multicolumn{2}{|c|}{ Non-White (n=339) } & \multicolumn{2}{|c|}{ White, non-Hispanic $(n=264)$} \\
\hline & $\mathrm{n}(\%)$ & $95 \% \mathrm{CI}$ & $\mathrm{n}(\%)$ & $95 \% \mathrm{CI}$ & $\mathrm{n}(\%)$ & $95 \% \mathrm{CI}$ & $\mathrm{n}(\%)$ & $95 \% \mathrm{CI}$ & $\mathrm{n}(\%)$ & $95 \% \mathrm{CI}$ \\
\hline \multicolumn{11}{|c|}{ Condition 1: Do you consider yourself to be: } \\
\hline $\begin{array}{l}\text { Heterosexual or } \\
\text { straight }\end{array}$ & $426(69.6)$ & 66 to 73 & $125(80.6)$ & 74 to 87 & $301(65.9)$ & 62 to 70 & $254(74.9)$ & 70 to 80 & $165(62.5)$ & 57 to 68 \\
\hline Gay or lesbian & $43(7.0)$ & 5 to 9 & $13(8.4)$ & 4 to 13 & $30(6.6)$ & 4 to 9 & $17(5.0)$ & 3 to 7 & $26(9.8)$ & 6 to 13 \\
\hline Bisexual & $134(21.9)$ & 19 to 25 & $13(8.4)$ & 4 to 13 & $121(26.5)$ & 22 to 31 & $63(18.6)$ & 14 to 23 & $70(26.5)$ & 21 to 32 \\
\hline Queer & N/A & N/A & N/A & N/A & N/A & N/A & N/A & N/A & N/A & N/A \\
\hline Asexual & N/A & N/A & N/A & N/A & N/A & N/A & N/A & N/A & N/A & N/A \\
\hline Pansexual & N/A & N/A & N/A & N/A & N/A & N/A & N/A & N/A & N/A & N/A \\
\hline $\begin{array}{l}\text { Questioning/not } \\
\text { sure }\end{array}$ & N/A & N/A & N/A & N/A & N/A & N/A & N/A & N/A & N/A & N/A \\
\hline Other (specify) & N/A & N/A & N/A & N/A & N/A & N/A & N/A & N/A & N/A & N/A \\
\hline Missing & $9(1.5)$ & 0.5 to 2 & $4(2.6)$ & 0.1 to 5 & $5(1.1)$ & 0.1 to 2 & $5(1.5)$ & 0.2 to 3 & $3(1.1)$ & 0 to 2 \\
\hline
\end{tabular}

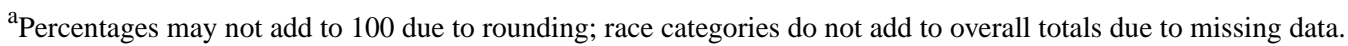

${ }^{\mathrm{b}} \mathrm{N} / \mathrm{A}$ : not applicable.

Table 2. Response distributions by sex and race in experimental condition $2{ }^{\text {a }}$

\begin{tabular}{|c|c|c|c|c|c|c|c|c|c|c|}
\hline \multirow[t]{3}{*}{ Sexual identity } & \multirow{2}{*}{\multicolumn{2}{|c|}{ Overall $(\mathrm{N}=642)$}} & \multicolumn{4}{|l|}{ Sex } & \multicolumn{4}{|l|}{ Race } \\
\hline & & & \multicolumn{2}{|c|}{ Male $(n=175)$} & \multicolumn{2}{|c|}{ Female $(n=467)$} & \multicolumn{2}{|c|}{ Non-White ( $\mathrm{n}=359)$} & \multicolumn{2}{|c|}{ White, non-Hispanic $(\mathrm{n}=277)$} \\
\hline & $\mathrm{n}(\%)$ & $95 \% \mathrm{CI}$ & $\mathrm{n}(\%)$ & $95 \% \mathrm{CI}$ & $\mathrm{n}(\%)$ & $95 \% \mathrm{CI}$ & $\mathrm{n}(\%)$ & $95 \% \mathrm{CI}$ & $\mathrm{n}(\%)$ & $95 \% \mathrm{CI}$ \\
\hline \multicolumn{11}{|c|}{$\begin{array}{l}\text { Condition 2: Below is a list of terms that people often } \\
\text { use to describe their sexuality or sexual orientation. } \\
\text { Please select the term that best applies to you. }\end{array}$} \\
\hline $\begin{array}{l}\text { Heterosexual or } \\
\text { straight }\end{array}$ & $423(65.9)$ & 62 to 70 & $133(76.0)$ & 70 to 82 & $290(62.1)$ & 58 to 67 & $250(69.6)$ & 65 to 74 & $170(61.4)$ & 56 to 67 \\
\hline Gay or lesbian & $30(4.7)$ & 3 to 6 & $20(11.4)$ & 7 to 16 & $10(2.1)$ & 0.8 to 3 & $10(2.8)$ & 1 to 5 & $19(6.9)$ & 4 to 10 \\
\hline Bisexual & $111(17.3)$ & 14 to 20 & $15(8.6)$ & 4 to 13 & $96(20.6)$ & 17 to 24 & $51(14.2)$ & 11 to 18 & $59(21.3)$ & 16 to 26 \\
\hline Queer & $20(3.1)$ & 2 to 4 & $1(0.6)$ & 0 to 2 & $19(4.1)$ & 2 to 6 & $9(2.5)$ & 0.8 to 4 & $11(4.0)$ & 2 to 6 \\
\hline Asexual & $5(0.8)$ & 0.1 to 2 & $1(0.6)$ & 0 to 2 & $4(0.9)$ & $\begin{array}{l}0.04 \text { to } \\
2\end{array}$ & $3(0.8)$ & 0 to 2 & $2(0.7)$ & 0 to 2 \\
\hline Pansexual & $15(2.3)$ & 1 to 3 & $3(1.7)$ & 0 to 4 & $12(2.6)$ & 1 to 4 & $10(2.8)$ & 1 to 5 & $5(1.8)$ & 0.2 to 3 \\
\hline $\begin{array}{l}\text { Questioning/not } \\
\text { sure }\end{array}$ & $32(5.0)$ & 3 to 7 & $1(0.6)$ & 0 to 2 & $31(6.6)$ & 4 to 9 & $22(6.1)$ & 4 to 9 & $9(3.2)$ & 1 to 5 \\
\hline Other (specify) & $5(0.8)$ & 0.1 to 2 & $0(0)$ & 0 to 0 & $5(1.1)$ & 0.2 to 2 & $3(0.8)$ & 0 to 2 & $2(0.7)$ & 0 to 2 \\
\hline Missing & $1(0.2)$ & 0 to 0.5 & $1(0.6)$ & 0 to 2 & $0(0)$ & 0 to 0 & $1(0.3)$ & 0 to 0.9 & $0(0)$ & 0 to 0 \\
\hline
\end{tabular}

${ }^{\text {a}}$ Percentages may not add to 100 due to rounding; race categories do not add to overall totals due to missing data.

An additional indicator of question performance is participants' willingness to respond to the question they received. As noted above, if some respondents felt that the shorter version of the question did not well represent their actual sexual identities, or if they were unsure of their identities, then we should expect to see a greater propensity toward item nonresponse than in the longer, more complete version of the question. To test this hypothesis, we estimated a logistic regression in which item nonresponse was regressed on a dummy treatment variable.
Indeed, compared with respondents answering the longer version of the question, those answering the shorter version had substantially greater odds of skipping the question altogether (odds ratio 9.57, 95\% CI 1.21-75.74; $P=.03$ ). Additionally, this has important implications for survey design: if survey questions are used as screeners and branch to additional items based on the sexual identity measure, then the magnitude of the impact of item nonresponse will increase. 


\section{Discussion}

Considered together, the comparison of response distributions (Tables 1 and 2) and the analysis of respondents' willingness to answer the question they received cast doubt on the appropriateness of the shorter, 3-category approach to measuring sexual identity. The longer item presents a descriptively richer picture of respondents' identities and induced significantly lower odds of item nonresponse. Furthermore, if the limited, shorter survey question makes respondents feel excluded, it could result in further stigmatizing or marginalizing individuals with nonnormative sexual identities [23]. Given that sexual minorities are more likely to experience negative health outcomes and report higher levels of some risk behaviors, these findings warrant attention from those aiming to study such outcomes and accurately describe their prevalence among various groups in the United States [1]. This is especially so given that sexual minorities are not a homogenous group in terms of health outcomes [1].
This study has limitations. Given that respondents were randomized between question versions, the internal validity of the study is high. However, this sample consisted only of young adults between the ages of 18 and 21. Further research should explore whether the impact of receiving one question version over another varies by respondent age. Moreover, our experimental respondents all live at least four months of the year in New Jersey. If comfort levels with revealing information about one's sexual identity vary regionally, the sizes of the treatment effects presented here may also vary if this experiment were fielded in other parts of the country or nationally.

To conclude, the evidence presented here favors the use of a longer, more detailed approach to measuring sexual identity in epidemiological research. This measure will likely allow researchers to produce more accurate estimates of health behaviors and outcomes among sexual minorities, given that respondents are less likely to skip the question, compared with the shorter item. Furthermore, accounting for the fluidity of sexual identity in the survey question will help to improve inclusion and representation in survey research among sexual minorities [23].

\section{Acknowledgments}

The research reported here was supported in part by the National Cancer Institute (NCI) and Food and Drug Administration (FDA) Center for Tobacco Products (CTP) under U54CA229973 and a contract from the New Jersey Department of Health (NJDOH). The content is solely the responsibility of the authors and does not necessarily represent the official views of the NCI, the FDA, or the New Jersey Department of Health.

\section{Conflicts of Interest}

None declared.

\section{Multimedia Appendix 1}

Sample Demographics.

[DOCX File, 32 KB-Multimedia Appendix 1]

\section{References}

1. Institute of Medicine. The Health of Lesbian, Gay, Bisexual, and Transgender People: Building a Foundation for Better Understanding. Washington, D.C: The National Academies Press; 2011.

2. Gonzales G, Przedworski J, Henning-Smith C. Comparison of Health and Health Risk Factors Between Lesbian, Gay, and Bisexual Adults and Heterosexual Adults in the United States: Results From the National Health Interview Survey. JAMA Intern Med 2016 Sep 01;176(9):1344-1351. [doi: 10.1001/jamainternmed.2016.3432] [Medline: 27367843]

3. Beach LB, Elasy TA, Gonzales G. Prevalence of Self-Reported Diabetes by Sexual Orientation: Results from the 2014 Behavioral Risk Factor Surveillance System. LGBT Health 2018;5(2):121-130 [FREE Full text] [doi: 10.1089/lgbt.2017.0091] [Medline: 29377760]

4. Dahlhamer JM, Galinsky AM, Joestl SS, Ward BW. Barriers to Health Care Among Adults Identifying as Sexual Minorities: A US National Study. Am J Public Health 2016 Jun;106(6):1116-1122. [doi: 10.2105/AJPH.2016.303049] [Medline: $\underline{26985623]}$

5. Fredriksen-Goldsen KI, Kim H, Shui C, Bryan AEB. Chronic Health Conditions and Key Health Indicators Among Lesbian, Gay, and Bisexual Older US Adults, 2013-2014. Am J Public Health 2017 Aug;107(8):1332-1338 [FREE Full text] [doi: 10.2105/AJPH.2017.303922] [Medline: 28700299]

6. Gonzales G, Henning-Smith C. Health Disparities by Sexual Orientation: Results and Implications from the Behavioral Risk Factor Surveillance System. J Community Health 2017 Dec 2;42(6):1163-1172. [doi: 10.1007/s10900-017-0366-z] [Medline: 28466199]

7. Gonzales G, Zinone R. Cancer diagnoses among lesbian, gay, and bisexual adults: results from the 2013-2016 National Health Interview Survey. Cancer Causes Control 2018 Sep;29(9):845-854. [doi: 10.1007/s10552-018-1060-x] [Medline: $\underline{30043193]}$ 
8. Schuler MS, Rice CE, Evans-Polce RJ, Collins RL. Disparities in substance use behaviors and disorders among adult sexual minorities by age, gender, and sexual identity. Drug Alcohol Depend 2018 Aug 01;189:139-146 [FREE Full text] [doi: 10.1016/j.drugalcdep.2018.05.008] [Medline: 29944989]

9. Hoffman L, Delahanty J, Johnson SE, Zhao X. Sexual and gender minority cigarette smoking disparities: An analysis of 2016 Behavioral Risk Factor Surveillance System data. Prev Med 2018 Aug;113:109-115 [FREE Full text] [doi: 10.1016/j.ypmed.2018.05.014] [Medline: 29763683]

10. Jackson CL, Agénor M, Johnson DA, Austin SB, Kawachi I. Sexual orientation identity disparities in health behaviors, outcomes, and services use among men and women in the United States: a cross-sectional study. BMC Public Health 2016 Aug 17;16(1):807 [FREE Full text] [doi: 10.1186/s12889-016-3467-1] [Medline: 27534616]

11. Lunn MR, Cui W, Zack MM, Thompson WW, Blank MB, Yehia BR. Sociodemographic Characteristics and Health Outcomes Among Lesbian, Gay, and Bisexual U.S. Adults Using Healthy People 2020 Leading Health Indicators. LGBT Health 2017 Aug;4(4):283-294 [FREE Full text] [doi: 10.1089/lgbt.2016.0087] [Medline: 28727950]

12. Schuler MS, Dick AW, Stein BD. Sexual minority disparities in opioid misuse, perceived heroin risk and heroin access among a national sample of US adults. Drug Alcohol Depend 2019 Aug 01;201:78-84 [FREE Full text] [doi: 10.1016/j.drugalcdep.2019.04.014] [Medline: 31200278]

13. Wheldon CW, Kaufman AR, Kasza KA, Moser RP. Tobacco Use Among Adults by Sexual Orientation: Findings from the Population Assessment of Tobacco and Health Study. LGBT Health 2018 Jan;5(1):33-44 [FREE Full text] [doi: 10.1089/lgbt.2017.0175] [Medline: 29324177]

14. Perez-Stable E. Director's Message: Sexual and Gender Minorities Formally Designated as a Health Disparity Population for Research Purposes. Bethesda, MD: National Institute on Minority Health and Health Disparities; 2016. URL: https:/ /www.nimhd.nih.gov/about/directors-corner/messages/message 10-06-16.html [accessed 2021-11-11]

15. Patterson JG, Jabson JM, Bowen DJ. Measuring Sexual and Gender Minority Populations in Health Surveillance. LGBT Health 2017 Apr;4(2):82-105 [FREE Full text] [doi: 10.1089/lgbt.2016.0026] [Medline: 28287877]

16. Wolff M, Wells B, Ventura-DiPersia C, Renson A, Grov C. Measuring Sexual Orientation: A Review and Critique of U.S. Data Collection Efforts and Implications for Health Policy. J Sex Res 2017 Dec 23;54(4-5):507-531. [doi: 10.1080/00224499.2016.1255872] [Medline: 28010119]

17. Measuring Sex, Gender Identity, and Sexual Orientation for the National Institutes of Health. Woods Hole, MA: The National Academies of Sciences, Engineering, and Medicine; 2021. URL: https://www8.nationalacademies.org/pa/projectview. aspx?key=52328 [accessed 2021-11-11]

18. Dillman DA, Smyth JD, Christian LM. Internet, Phone, Mail, and Mixed-Mode Surveys: The Tailored Design Method (4th Edition). Hoboken, NJ: Wiley; 2014.

19. National Center for Health Statistics (Centers for Disease Control and Prevention). 2021 National Health Interview Survey (NHIS) Questionnaire. 2021. URL: https://ftp.cdc.gov/pub/Health Statistics/NCHS/Survey Questionnaires/NHIS/2021/ EnglishQuest.pdf [accessed 2021-11-11]

20. Centers for Disease Control and Prevention. 2019 BRFSS Questionnaire. Atlanta, GA: Centers for Disease Control and Prevention; 2019. URL: https://www.cdc.gov/brfss/questionnaires/pdf-ques/2019-BRFSS-Questionnaire-508.pdf [accessed 2021-11-11]

21. 2019 National Survey on Drug Use and Health (NSDUH): Final CAI Specifications for Programming. Rockville, MD: Substance Abuse and Mental Health Services Administration, Center for Behavioral Health Statistics and Quality; 2018. URL: https://www.datafiles.samhsa.gov/sites/default/files/field-uploads-protected/studies/NSDUH-2019/ NSDUH-2019-datasets/NSDUH-2019-DS0001/NSDUH-2019-DS0001-info/NSDUH-2019-DS0001-info-questionnaire-specs. pdf [accessed 2021-11-11]

22. Gold M. The ABCs of L.G.B.T.Q.I.A.+. The New York Times. 2018. URL: https://www.nytimes.com/2018/06/21/style/ lgbtq-gender-language.html [accessed 2021-11-11]

23. Suen LW, Lunn MR, Katuzny K, Finn S, Duncan L, Sevelius J, et al. What Sexual and Gender Minority People Want Researchers to Know About Sexual Orientation and Gender Identity Questions: A Qualitative Study. Arch Sex Behav 2020 Oct 01;49(7):2301-2318 [FREE Full text] [doi: 10.1007/s10508-020-01810-y] [Medline: 32875381]

\section{Abbreviations}

FDA: Food and Drug Administration

NCI: National Cancer Institute

PACE NJ: Policy and Communication Evaluation: New Jersey 
Edited by Y Khader; submitted 21.07.21; peer-reviewed by P Serrano, YL Cheong; comments to author 16.08.21; revised version received 18.08.21; accepted 19.08.21; published 13.12.21

Please cite as:

Young WJ, Bover Manderski MT, Ganz O, Delnevo CD, Hrywna M

Examining the Impact of Question Construction on Reporting of Sexual Identity: Survey Experiment Among Young Adults

JMIR Public Health Surveill 2021;7(12):e32294

URL: https://publichealth.jmir.org/2021/12/e32294

doi: $10.2196 / 32294$

PMID:

CWilliam J Young, Michelle T Bover Manderski, Ollie Ganz, Cristine D Delnevo, Mary Hrywna. Originally published in JMIR Public Health and Surveillance (https://publichealth.jmir.org), 13.12.2021. This is an open-access article distributed under the terms of the Creative Commons Attribution License (https://creativecommons.org/licenses/by/4.0/), which permits unrestricted use, distribution, and reproduction in any medium, provided the original work, first published in JMIR Public Health and Surveillance, is properly cited. The complete bibliographic information, a link to the original publication on https://publichealth.jmir.org, as well as this copyright and license information must be included. 